\title{
More Is (Not Always) Better: A Multi-Year Analysis of Advertising Effects on Ad Recall
}

\author{
Kristen L. Sussman \\ University of Texas at Austin \\ Laura F. Bright \\ University of Texas at Austin \\ Gary B. Wilcox \\ University of Texas at Austin
}

Using data from 46 businesses and over 21,000 ads, this study provides an analysis of the relationship between advertising spend, engagement and ad recall on Facebook. An initial analysis reveals that advertising spend, and post comments are positively associated with ad recall, while frequency is negatively associated. A second analysis, segmented the data by the advertiser objective of brand awareness, video views or post engagement and reveals additional insight into the relationships between the variables. It is concluded that Facebook offers an effective channel to drive recall, but that advertisers should be careful to avoid ad fatigue. In total, the results provide evidence that Facebook advertising can easily become intrusive, and that brand awareness driven advertising exhibit the most promising relationship with ad recall.

Keywords: engagement, brand communication, social media, recall, ad technology, Facebook advertising, ad fatigue, advertising effects

\section{INTRODUCTION}

Social media has rapidly become a part of people's everyday life. Offering the ability to connect, communicate and share, U.S. consumers spend about two hours daily on social media (Clement, 2019). While overall social media use and advertising expenditures continue to increase, much remains to be understood about the effects of brand communication in social media, especially regarding engagement and message recall. On one hand, Facebook is especially attractive to advertisers for its targeting attributes like custom audiences (Venkatadri et al. 2018) as well as its user-facing affordances (Bossetta, 2018; Davis \& Chouinard, 2016). Providing a surplus of data, tools like Facebook are becoming increasingly useful to understand consumer behavior, engagement, and overall advertising effectiveness. However, on the other hand, little is understood about effects of advertising recall. Advancing this challenge is the fact that social media technologies are operated largely by invisible algorithms (Bucher, 2017). However, to mitigate this and explore effects related to ad recall on Facebook, this study examines a large data set sourced from a 
sample of 46 national advertisers. The broad goal of this paper is to advance our theoretical understanding of advertising effects through brand communications on social media through the lens of Facebook engagement.

Defined as the estimated number of people to recall an ad within two days of being served the ad, the Facebook ad recall lift metric has become a key component of the Facebook Ads Manager, yet little empirical research has examined what drives ad recall among Facebook consumers. Given the objective of this research, a longitudinal analysis of predictor variables of advertising spend, engagement and frequency are used to analyze effects on ad recall as measured by the Facebook Estimated Ad Recall Lift metric. Relationships are examined using datasets extrapolated from 46 businesses and their associated Facebook ad data, yielding more than 21,000 ads scheduled between January 1, 2017, and May 28, 2020, and provide an empirical understanding of the significant predictors of ad recall.

\section{LITERATURE REVIEW}

\section{Social Media Advertising Effects}

Brand communication in social media is any piece of brand-related communication "distributed via social media that enables internet users to access, share, engage with, add to, and co-create" (Alhabash, Mundel, \& Hussain, 2017, p. 286). Brand communication research on Facebook has shown impressions, page views, likes and user contributions can benefit short-term and long-term effects on sales (Brettel, Reich, Gavilanes, \& Flatten, 2015). Another resulting effect, electronic word of mouth (eWOM), is any online statement made by either potential or current customers (Hennig-Thurau, Gwinner, Walsh \& Gremler, 2004). Facebook posts are an effective advertising stimulus for generating consumer word-ofmouth behavior (Kim, Kim \& Kim, 2019). Brand communication on Facebook can generate beneficial ad effects even beyond eWOM.

Elaboration, for instance, relates to how information retained in a person's working memory integrates with past knowledge (MacInnis \& Price, 1987, p. 475) and is an indication of the amount, complexity, or range of cognitive thinking resulting from a stimulus (McQuarrie \& Mick, 1999). Behavioral engagement relating to these brand communications has been defined as user engagement including actions such as likes, shares, comments and clicks (Lee, Hosanagar, \& Nair, 2018). Engagement as a research focus has received a variety of definitions. Consumer engagement, especially in online context, is highly dynamic in relation to the interactive nature of brand communities (Brodie, Ilic, Juric \& Hollebeek, 2013). It's easy to imagine how one type of engagement behavior may elicit more cognitive elaboration than another. For example, when a user clicks on a link in their news feed, other users cannot see that behavior. Other actions such as commenting or sharing are public (Stroud, 2019) and likely require more cognitive consideration by the user before engaging. Alternatively, affective elaboration is induced through message-related feelings while cognitive elaboration refers more specifically to message related thoughts (Kim, Baek \& Choi, 2012). When someone is exposed to a stimulus, such as a social media post, they will exhibit messagerelated responses along both affective and cognitive spectrums (Kim et al., 2012, Batra \& Stephens, 1994, Kempf, 1999). Consequently, through the elaboration likelihood model (Petty and Cacioppo, 1986) we know that the amount of cognitive elaboration a consumer devotes to processing a message contributes toward attitude formation.

Media interactivity can also drive engagement as a byproduct of strong cognitive focus (e.g., Busselle \& Bilandzic, 2009; Klimmt \& Vorderer, 2003; O’Brien \& Toms, 2010; Slater \& Rouner, 2002). Further research suggests that cognitive elaboration plays the primary role for attitude formation (e.g., Petty \& Cacioppo, 1986; Petty \& Wegener, 1999), while others suggest that affective elaboration is the primary influencer on attitude (e.g., Pham, Cohen, Pracejus \& Hughes, 2001; Kim \& Morris, 2007). It's also been argued that engagement itself should not be regarded as an effectiveness metric but instead considered a psychological process leading to reach through virality (Alhabash, McAlister \& Hagerstrom, 2015). Even if engagement is conceptualized in these terms, what use is reach if brand communication lacks recall?

Physical interaction can positively predict recall memory (Oh, Bellur \& Sundar, 2018). However, the effects were associated with a website, and may be less meaningful than the cognitive elaboration occurring 
at the message-level. Within Facebook, posts have been found to elicit both affective and cognitive elaboration. A "like" was more closely related to affective elaboration, while comments and shares were cognitively triggered (Kim \& Yang, 2017). On the other hand, message-related thoughts can also be reduced in some settings (Oh \& Sundar, 2015). Therefore, we predict that while brand communication in social media can be processed via affective or cognitive routes of elaboration, recall will be related more highly to those consumer behaviors that exhibit higher cognitive elaboration. That is, cognitive elaboration will occur, and relate to some degree, to the message-level engagement.

H1: Engagement factors that are associated with higher levels of cognitive elaboration, such as comments and shares, will significantly predict recall whereas reactions and clicks will not.

\section{Facebook Effectiveness and Advertising Recall}

Behavioral engagement measures such as the "like" have been found to be superficially valuable (Precourt, 2014; Rappaport, 2014). Alternatively, ad recall has driven decades worth of research interest. Highlighting its prestige, it's been stated that "if a target audience cannot remember a marketer's message, advertising largely becomes a waste of time" (Precourt, 2016). For instance, recall on television has been shown to be related to arousal (Pavelchak, 1988). In an online setting, length of exposure to a web banner advertisement has been found to predict strength in recall (Danaher \& Mullarkey, 2003). Social media may provide the right setting (e.g., news feed, mobile phones) for engagement related arousal.

Behavioral measures of likes, clicks and comments may be experienced differently than psychological processes of engagement. These differences can explain some of the variations across current definitions. An additional metric of engagement on Facebook is video consumption, which measures a user's average video playtime of an advertisement. One related theory of cognitive elaboration is narrative advertising which can explain product consumption during a story (Chang, 2009). Narrative advertising is defined as having a story-like structure (Boller \& Olson, 1991). While narrative advertising has been shown to be more mentally stimulating than other advertising appeals (Ching, Tong, Chen \& Chen, 2013), research has also found some discrepancy when using the ELM to explain cognitive elaboration in narrative advertising (Green \& Brock, 2002; Appel \& Richter, 2010). Narrative effectiveness can vary from person to person (Brechman \& Purvis, 2015), or across fluctuations in narrative structure (Feng, Xie, \& Lou, 2019). Facebook video, and most social media content in general, tend to consist of shorter video formats than traditional advertisements such as radio or television. Taken together, the following hypothesis is proposed:

\section{H2: Video average play time will not be significantly related to ad recall.}

\section{The Impact of "Like"}

Facebook advertisers benefit from several advertising effects from more effectively leveraging their presence on Facebook to better understanding their audience reach (Lipsman. Mudd, Rich \& Bruich, 2012). The Ad Recall Lift metric, as reported by Facebook, provides advertisers a measurement to better understand not only their reach, but also how consumers recall ads after exposure. In the comprehensive collection of literature on the topic of ad recall (e.g., Smit, Van Meurs \& Neijens, 2006; Wouters \& Wetzels, 2006; King \& Tinkham, 1989), the metric is operationalized as either aided or unaided recall and consumers' ability to score well on these measures is a key component for advertisers to evaluate campaign success (Kent, 2002). While the measure of ad recall is largely supported in traditional advertising research, it is equally important to online and social media advertising. Effectiveness research has also been criticized for focusing too heavily upon short-term measures like sales or clicks (Araujo et al., 2020; Lambert, 2018). Thus, advertisers who include Facebook in their media mix can benefit by understanding the ad recall data provided by the platform. Information processing has also been linked with recall (Chung \& Zhao, 2003; Aaker \& Myers, 1987; Burke \& Edell, 1986) and is an expected benefit of advertising on Facebook.

H3: An increase in ad spend will be positively associated with message recall (e.g., Facebook Ad Recall Lift). 


\section{Ad Fatigue}

Repetition also relates to ad effectiveness but is rarely included in most advertising research (Nan \& Faber, 2004). Initial repetition has been shown to improve brand preference, yet too many additional repetitions can quickly create negative effects (Batra \& Ray, 1986). Commonly called ad fatigue, the precision targeting available to advertisers on social media may trigger this negative effect more easily. Personalization, heightened through algorithmic targeting, can increase the likelihood for a person to tire of an online advertisement (Abrams \& Vee, 2007). As a byproduct of too many impressions and not enough reach, the measure of frequency will increase. As a key issue relating to online advertisements, researchers have begun to employ new algorithmic tactics to predict a person's psychological state and potentially improve this negative effect (Moriwaki, Fujita, Yasui \& Hoshino, 2019). As an issue potentially heightened in online advertising, we predict that recall may have a negative relationship with frequency.

\section{H4: An increase in ad frequency will be negatively associated with ad recall.}

\section{METHOD}

\section{Data Acquisition}

All data were obtained from the Facebook Ads Manager and included weekly reports on advertising related predictors across 46 U.S. based businesses and 21,334 ads. Advertising messages sponsored by these businesses were distributed across the Facebook audience network using Facebook Ads Manager. Facebook users had the opportunity to interact with these ads in their newsfeeds on either Facebook or Instagram. The businesses used in this study spanned a broad range of industries including quick service restaurants, fine dining, non-profit, banking, energy, biopharmaceutical, health and wellness, personal beauty products, education, technology (i.e., both business to business and business to consumer) and consumer goods. After removing all campaigns that didn't use one of the three objectives that Facebook associates with brand awareness (e.g., post engagement, brand awareness, or video views) the remaining advertising data included 4,656 total advertising campaigns. The Facebook Ads Manager reports data at various levels including the account level (e.g., by client), the campaign level (e.g., by objective), and ad set level (e.g., by creative). These three groupings are associated with the ad creation workflow in Facebook Ads Manager (Facebook, 2020).

Predictor variables included in this analysis are post reactions, post comments, post shares, link clicks, ad frequency and ad spend and included in Table 1. The dependent variable was Facebook Ad Recall Lift, which is referred to more simply as ad recall throughout our paper, defined as the estimated number of people to recall an ad during a given period based on the Facebook Ads Manager algorithm. Facebook operationalizes this study's dependent variable as estimated ad recall lift (people) and is defined by the Facebook Help Center (2019) as the incremental number of people that would answer "Yes" to "Do you recall seeing an ad from [example brand] in the last two days?"

The incremental number of people is calculated by asking both an exposed group who have seen the ad (i.e., within two days of it being served) and a control group who haven't seen the ad the same question and then calculating the difference between the two groups. Data was collected on a consecutive, weekly basis, at the campaign level and resulted in 187 observations. Once all data was exported, it was then combined, cleaned, and stripped of identifiers before being analyzed. The raw data resulted in 187 observations measured as a weekly overview of 46 advertisers from ads that were scheduled between January 1, 2017, and May 28, 2020.

\section{Data Analysis}

In early 2010, the Social Media Performance Model (SMPM) was developed as a predictive multivariate statistical model using multiple variables to quantify social media performance (Wilcox \& Kim, 2012). The SMPM utilizes a time series analysis approach to examine the relationship of organic and paid social media to various key performance indicators (KPIs). As a method for social media data analysis, this approach uses predictive analytics to arrive at a predictive model of future observations and is especially 
useful for the goal of this paper with its utility for "establishing research relevance by evaluating the discrepancy between theory and practice" (Shmueli \& Koppius, 2011). Previous research using the social media performance model (SMPM) has effectively examined social media effects across a wide variety of brands from non-profits, to B2C and B2B (Wilcox \& Moore, 2016; Wilcox \& Sussman, 2014,) and most recently influencer marketing (Sciarrino, Wilcox, \& Chung, 2020). This paper provides a continued evaluation of the SMPM focused on social media advertising with the goal being identification of the predictors significantly impacting the Facebook Ad Recall Lift measure as well as the importance of those identified variables. The predictor variables described in Table 1, Table 2 and Table 3 were used in a generalized least-squares regression equation that used Facebook Ad Recall Lift as the dependent measure.

Prior to the analysis, all variables underwent a log-transformation to aid with final interpretation. A stepwise regression analysis with backwards elimination of non-significant predictors was used in determining which variables were significant predictors of the dependent variable series. For each model, the least significant predictors were dropped, and additional regression analyses were performed until a final model for the dependent variable was obtained with all variables significant $(p<.05)$.

Because of the serious problems autocorrelation can present in analysis of time-series data, a generalized least-squares regression approach that uses estimates of autocorrelation in the model's residuals in estimating structural parameters and significance levels was employed. The SAS AUTOREG ${ }^{1}$ procedure was utilized considering possible significant autocorrelation at lags of one, two and three weeks $\mathrm{s}^{\mathrm{i}}$. Estimates of autocorrelations, which include the estimates of the autocovariances, the autocorrelations, and a graph of the autocorrelation are displayed in the output. If autocorrelation correction is needed, the autoregressive error model using stepwise autoregression is employed. The stepwise autoregression method initially fits a high-order model with many autoregressive lags and then sequentially removes autoregressive parameters until all remaining autoregressive parameters have significant $t$ tests. The stepwise autoregressive process is performed using the Yule-Walker method. The maximum likelihood estimates are produced after the order of the model is determined from the significance tests of the preliminary Yule-Walker estimates.

\section{RESULTS}

Our first study focused on the Facebook advertiser's dataset at the aggregate level and included seven predictor variables which were hypothesized to relate to our dependent variable of interest, ad recall. The seven variables of predictive interest were ad spend, frequency and five message-level engagements factors (e.g., shares, comments, clicks, and video views). Using two studies, the seven predictors were analyzed across models using time series analysis to understand how these variables of interest relate to ad recall in the Facebook advertising environment. Because our focus relates to a comparison of these predictors, it can be useful to review raw correlations among the social media variables. This helps to provide perspective of the time-series correlations and relationships between the ad recall predictors without any lags, as discussed below, prior to running the full analysis (Table 2).

The correlations include 178 observations measuring weekly levels of advertising spend, post engagement and frequency. In total, these measures average out to a somewhat low correlation $(r=.22)$ and even among the five brand communication engagement measures (e.g., reactions, shares, clicks and comments), the average correlations are not particularly high $(r=.31)$. There is also substantial variation across the correlations and between different measures.

\section{Analysis 1}

As hypothesized, four different hypotheses were designed to test ad recall effects based on traditional components of advertising and engagement-based message-level behaviors; those hypotheses stated that post comments and post shares (H1), video average view time (H2) ad spend (H3), and frequency (H4) would predict (or not), the effect of ad recall. The full and final regression models with the statistically significant variables are presented in Table 3. 
TABLE 1

SUMMARY OF VARIABLES (FACEBOOK AND INSTAGRAM, WEEKLY)

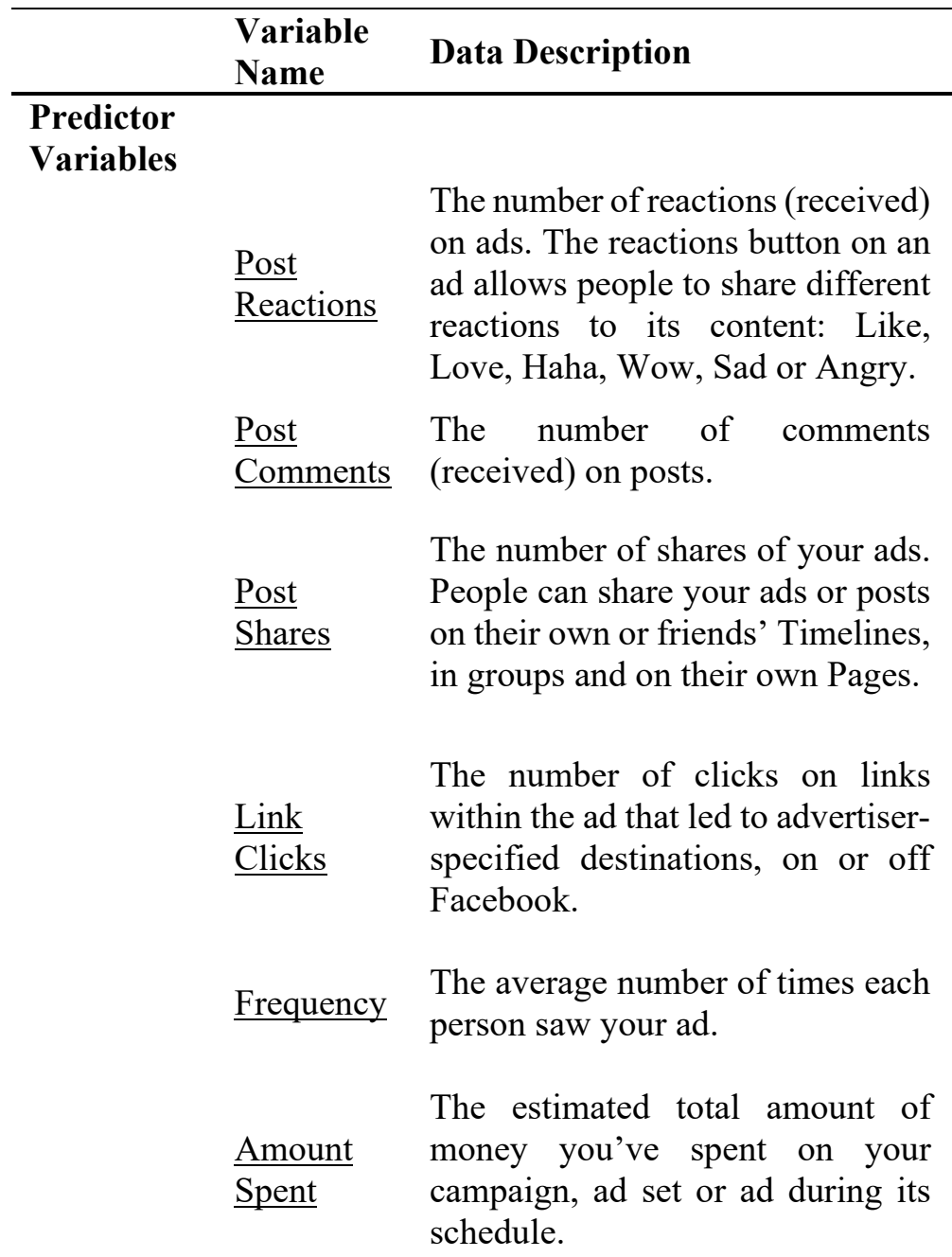

\section{Dependent}

Variable

How its Calculated

The post reactions metric counts all reactions that people had to your ads while they were running.

The post comments metric counts all comments that people made on your ads while they were running.

The metric counts shares of your ads while they were running. It may also include Instagram shares sent to people's inboxes.

These metric counts link clicks on the ad's text, media, or call-to-action, that link to destinations or experiences specified by the advertiser. This metric excludes clicks on content or links in the comments section of a post.

Frequency is calculated as impressions divided by reach.

This metric is used as the numerator for calculating all cost per action or cost per result metrics. If your ads are currently running, these numbers may be an estimate, since it can take up to 48 hours for ad results to be processed.

The incremental number is calculated by asking both an exposed group (who have seen the ad) and a control group (who haven't seen the ad) the same question and then calculating the difference between the two groups.

Note (1) All data included in the study is sourced from Facebook Ads Manager. (2) Data descriptions and how they are calculated are sourced from the Facebook Help Center | Facebook. (n.d.). Retrieved June 9, 2020, from https://www.facebook.com/help/

The results of the final regression models and the hypotheses are discussed below. Considering significant autocorrelation at lags of up to three weeks, three predictor variables were found to be significantly related to ad recall including post comments, ad frequency, and ad spend. The final model explained $93 \%$ of the variance for the given predictor variables for ad recall with a high degree of accuracy 
that is evidenced by the noted R square value, as well as the mean average percentage error (MAPE), and root mean square error (RMSE) values that demonstrate the model's fit.

TABLE 2

PEARSON CORRELATIONS OF PREDICTOR VARIABLES $(\mathbf{N}=178)$

\begin{tabular}{llllllll}
\hline Predictors & 1 & 2 & 3 & 4 & 5 & 6 & 7 \\
\hline Post Reactions & 1.00 & & & & & & \\
Post Comments & $0.37^{* * *}$ & 1.00 & & & & & \\
Post Shares & $0.36^{* * *}$ & $0.83^{* * *}$ & 1.00 & & & & \\
Link Clicks & $0.22^{* *}$ & $0.35^{* * *}$ & $0.54^{* * *}$ & 1.00 & & & \\
Frequency & $-0.06^{* * *}$ & -0.01 & -0.06 & -0.05 & 1.00 & & \\
Ad Spend & $0.7^{* * *}$ & $0.4^{* * *}$ & $0.4^{* * *}$ & $0.25^{* * *}$ & 0.14 & 1.00 & \\
Video Avg. Playtime & & & & & & & \\
(in seconds) & -0.04 & 0.00 & 0.12 & $0.24 * *$ & 0.07 & 0.02 & 1.00 \\
$M$ & 3792 & 108.22 & 202.71 & 600.28 & 1.45 & 2221 & 90.72 \\
$S D$ & 9118 & 106.01 & 176.24 & 615.46 & 0.24 & 2280 & 101.69 \\
\hline
\end{tabular}

Note 1$) * p<.05, * * p<.01, * * * p<.00$

The B (beta) value produced by the regression analysis provides insight by revealing the importance of each of the significant predictor variables on Facebook ad recall. The beta value is a measure of how strongly each predictor variable influences the dependent variable and is measured in units of standard deviation. The higher the beta value, the greater the impact of the predictor variable on the dependent variable. In support of $\mathrm{H} 3$, a $1 \%$ increase in ad spend was associated with a $0.72 \%$ increase in the ad recall score. Expressed another way, a $\$ 1$ increase in ad spend was associated with an average increase of 1,203 in Facebook ad recall. As defined by Facebook, the ad recall lift metric represents the number of people who remembered seeing the ad. Thus, an increase of $\$ 1$ in advertising spend, was associated with recall from an additional 1,203 people.

TABLE 3

MODEL 1 - FACEBOOK RECALL BY AGGREGATE PREDICTORS

\begin{tabular}{l|l|l|l|l|l|l}
\cline { 2 - 7 } & \multicolumn{2}{l|}{ Full Model } & \multicolumn{2}{l}{ Final Model } \\
$\left(\mathrm{R}^{2}=0.94, \mathrm{MAPE}=1.9, \mathrm{RMSE}=.1086\right)$ & \multicolumn{2}{l}{$\left(\mathrm{R}^{2}=0.93, \mathrm{MAPE}=1.9, \mathrm{RMSE}=.1091\right)$} \\
\hline Predictor & $\boldsymbol{B}$ Value & $\boldsymbol{t}$-ratio & $\boldsymbol{p}$-value & $\boldsymbol{B}$ Value & $\boldsymbol{t}$-ratio & $\boldsymbol{p}$-value \\
\hline Intercept & 1.8111 & 14.35 & $<.0001$ & & & \\
Post Reactions & -0.0523 & -1.38 & 0.1706 & & & \\
Post Comments & 0.1266 & 2.57 & 0.0111 & 0.1798 & 6.57 & $<.0001$ \\
Post Shares & 0.0917 & 1.54 & 0.1251 & & & \\
Link Clicks & 0.0324 & 0.0287 & 0.2606 & & & \\
Frequency & -0.6099 & -3.99 & $<.0001$ & -0.6049 & -4.07 & $<.0001$ \\
Ad Spend USD & 0.7297 & 18.79 & $<.0001$ & 0.7172 & 22.5 & $<.0001$ \\
Avg video playtime & -0.7297 & -0.27 & 0.7859 & & & \\
\hline
\end{tabular}


The average weekly recall score from this sample of advertisers was 37,135 and the average weekly spend was $\$ 2,221$. Further, H1 was partially supported with consideration to post comments but not post shares. Here the lower beta value explains that a $1 \%$ increase in post comments was associated with a $0.18 \%$ increase in ad recall. In other words, one post comment was associated with an average increase of 6,177 in ad recall. As noted previously, the average weekly recall was 37,137 and there was an average of 108 weekly post comments.

With concern to ad frequency, $\mathrm{H} 4$ was supported with the model finding that a $1 \%$ increase in ad frequency was associated with a $0.6 \%$ decrease in the ad recall score or stated another way, a 0.014 increase in frequency was associated with a decrease of 4.2 in ad recall. The average weekly recall score was 37,137 and average weekly frequency was 1.45 . Finally, $\mathrm{H} 3$, which predicted that average video view time would not be significantly related to ad recall, was also supported.

\section{Analysis 2}

The previous models examined advertising effects at an aggregate level which can enable the measurement of more subtle effects, especially when compared to sample sizes in traditional communications research (Monroe et al., 2015). Another advantage in our favor is that we may also segment the dataset based on previously theorized levels of importance that relate to the overall measure of ad recall. As is standard practice in advertising, a media plan will typically start with identifying an objective for their communications. Similarly, within Facebook, an advertiser also identifies their objective prior to running a campaign. For the results in our second analysis, we have segmented the full dataset into three smaller datasets organized by the advertising objective of either video views, post engagement or brand awareness. Thus, we rely on the intended goal of the advertiser for the second set of analyses.

Again, full, and final regression models and the statistically significant variables are presented in in Table 4. Again, the stepwise autoregressive process was performed using the Yule-Walker method, which resulted in identifying the predictor variables that significantly predict ad recall across the second, third and fourth groups of models.

The next model grouped advertising data by those advertisers who chose the brand awareness objective and explained $94 \%$ of the variance for the given predictor variables. Again, the model results all appear to demonstrate a good fit and again, we rely on the beta value to understand the importance of each significant predictor. Here, the average weekly recall score from this sample of advertisers was 22,240 and the average weekly number of post reactions, which was found to be a significant predictor, was 370 . The beta tells us that a $1 \%$ increase in post reactions is associated with a $0.21 \%$ increase in ad recall or interpreted another way, tells us that an increase in 1 post reaction is associated with an increase of 1,262 in ad recall.

For post shares, which was also found to be significant in this model, the beta results report that a $1 \%$ increase in post shares is associated with a $0.14 \%$ increase in ad recall, or that an increase in one post share is associated with an increase of 4,789 in ad recall. For advertisers seeking brand awareness, ad spend is again found to predict ad recall and tells us that a $1 \%$ increase in spend was associated with a $0.54 \%$ increase in ad recall. Thus, for this group of advertisers who had a weekly average spend of $\$ 892$, the model tells us that an increase in $\$ 1$ is associated with an increase of 1,346 in ad recall.

In the second study, the model of data that was segmented by advertisers who sought to achieve post engagement as their objective explained $92 \%$ of the variance. Of the significant predictors, this group of advertisers had a weekly average number of post reactions totaling 3,398, ad spend of $\$ 1,021$, post shares of 137 and ad frequency of 1.43. Here, a $\$ 1$ increase in ad spend was associated with an increase of 822 in ad recall. 
TABLE 4

FACEBOOK RECALL BY ADVERTISER OBJECTIVE

\begin{tabular}{|c|c|c|c|c|c|c|}
\hline \multicolumn{4}{|c|}{ Full Model } & \multicolumn{3}{|c|}{ Final Model } \\
\hline Predictors & B Value & t-ratio & p-value & B Value & t-ratio & p-value \\
\hline Brand Awareness & \multicolumn{3}{|c|}{$\begin{array}{l}\left(\mathrm{R}^{2}=0.94, \mathrm{MAPE}=4.18\right. \\
\mathrm{RMSE}=.1952)\end{array}$} & \multicolumn{3}{|c|}{$\begin{array}{l}\left(\mathrm{R}^{2}=0.94, \mathrm{MAPE}=4.31,\right. \\
\mathrm{RMSE}=.1977)\end{array}$} \\
\hline Intercept & 1.96 & 19.49 & $<.0001$ & 1.96 & 19.51 & $<.0001$ \\
\hline Post Reactions & 0.20 & 3.80 & 0.00 & 0.21 & 4.07 & $<.0001$ \\
\hline Post Comments & 0.02 & 0.44 & 0.66 & & & \\
\hline Post Shares & 0.13 & 2.01 & 0.05 & 0.14 & 2.72 & 0.01 \\
\hline Link Clicks & 0.04 & 1.57 & 0.12 & & & \\
\hline Frequency & -0.43 & -1.93 & 0.06 & & & \\
\hline AdSpend USD & 0.55 & 8.99 & $<.0001$ & 0.54 & 9.89 & $<.0001$ \\
\hline AVG video playtime & -0.07 & -1.21 & 0.23 & & & \\
\hline Post Engagement & \multicolumn{3}{|c|}{$\begin{array}{l}\left(\mathrm{R}^{2}=0.92, \mathrm{MAPE}=2.61,\right. \\
\mathrm{RMSE}=.1239)\end{array}$} & \multicolumn{3}{|c|}{$\begin{array}{l}\left(\mathrm{R}^{2}=0.92, \mathrm{MAPE}=2.64,\right. \\
\mathrm{RMSE}=.1247)\end{array}$} \\
\hline Intercept & 1.62 & 15.81 & $<.0001$ & 1.57 & 16.16 & $<.0001$ \\
\hline Post Reactions & -0.13 & -3.69 & 0.00 & -0.13 & -3.68 & 0.00 \\
\hline Post Comments & 0.06 & 1.31 & 0.19 & & & \\
\hline Post Shares & 0.21 & 4.53 & $<.0001$ & 0.24 & 8.02 & $<.0001$ \\
\hline Link Clicks & -0.04 & -1.70 & 0.09 & & & \\
\hline Frequency & -0.54 & -3.56 & 0.00 & -0.58 & -3.84 & $<.001$ \\
\hline AdSpend USD & 0.82 & 20.29 & $<.0001$ & 0.83 & 21.02 & $<.0001$ \\
\hline AVG video playtime & - & - & - & - & - & - \\
\hline Video Views & \multicolumn{3}{|c|}{$\begin{array}{l}\left(\mathrm{R}^{2}=0.93, \mathrm{MAPE}=3.9,\right. \\
\mathrm{RMSE}=.1819)\end{array}$} & \multicolumn{3}{|c|}{$\begin{array}{l}\left(\mathrm{R}^{2}=0.93, \mathrm{MAPE}=1.9,\right. \\
\mathrm{RMSE}=.1811)\end{array}$} \\
\hline Intercept & 1.79 & 22.43 & $<.0001$ & 1.76 & 27.85 & $<.0001$ \\
\hline Post Reactions & 0.15 & 3.10 & 0.00 & 0.1895 & 6.6 & $<.0001$ \\
\hline Post Comments & 0.00 & -0.05 & 0.96 & & & \\
\hline Post Shares & 0.06 & 0.99 & 0.32 & & & \\
\hline Link Clicks & 0.14 & 5.20 & $<.0001$ & 0.1433 & 5.73 & $<.0001$ \\
\hline Frequency & -1.02 & -6.49 & $<.0001$ & -1.0422 & -7.31 & $<.0001$ \\
\hline AdSpend USD & 0.60 & 14.48 & $<.0001$ & 0.5878 & 16.71 & $<.0001$ \\
\hline AVG video playtime & -0.03 & -0.50 & 0.62 & & & \\
\hline
\end{tabular}

Alternatively, an increase in one post share was associated with an increase of 1,779 ad recall. On the other hand, an increase of one post reaction was associated with a decrease of 39 in ad recall and an increase of 0.01 in frequency is associated with a decrease of 5,872 in ad recall. The final two predictors here, frequency and post reactions are significant, albeit negatively associated with ad recall.

The Video Views model presented results based on advertisers who had identified video views as their intended objective and explained $93 \%$ of the variance. Within this group of advertisers, the average weekly ad recall was 5,990 and was associated with an average weekly spend of $\$ 519$. Of the significant predictors, post reactions, clicks, frequency and ad spend are included in the final model. Here, frequency is the only negatively related significant predictor and an increase in $\$ 1$ is associated with an increase of 681 in ad recall. On the other hand, an increase in one post reaction is associated with less than 0.001 increase in ad recall, whereas an increase in on click is associated with an increase of 0.002 in ad recall. Finally, an increase in frequency of 0.02 is associated with a decrease of 6,229 in ad recall. 


\section{DISCUSSION}

This study used digital traces of consumer behavior that relate psychologically to the effects of brand communications within the social media environment. Not uncommon in time series analysis, the models explained between $92 \%$ and $94 \%$ of the variation in ad recall. Further attributing to this fit is likely the use of one platform (e.g., Facebook) as the single data source. At the aggregate level, the first model found evidence that three types of advertising effects were significantly related to ad recall in brand communications on Facebook. Post comments and ad spend (i.e., amount spent by the advertiser) not only exhibited positive relationships but also strong effects. Scholars (Fay, Keller \& Larkin, 2019) and practitioners have long touted the benefit of creating online "buzz", but this study provides context to the value of a comment as it relates to ad recall. For comparison, recall that our initial aggregate analysis found that each increase in \$1 was associated with an increase of 1,203 in ad recall. However, an increase in one post comment was associated with 6,177 in ad recall. Strikingly, post comments were only found to be significant at the aggregate level of analysis. However, these results are quite meaningful as suggested by both the cognitive elaboration that is likely related to a person commenting on the post as well as to the large increase in ad recall associated with one comment (see Table 5).

TABLE 5

BETA RELATIONSHIPS OF AD RECALL IMPACT BY PREDICTOR VARIABLE

\begin{tabular}{l|llllll}
\hline \multicolumn{1}{l}{} & $\begin{array}{l}\text { \$1 Increase } \\
\text { in Ad } \\
\text { Spend }\end{array}$ & \begin{tabular}{l}
0.05 \\
Increase in \\
\multicolumn{1}{l}{\begin{tabular}{l} 
Ad \\
\multicolumn{1}{l}{ Frequency }
\end{tabular}}
\end{tabular} & $\begin{array}{l}\text { 1 Increase } \\
\text { in Post } \\
\text { Comment }\end{array}$ & $\begin{array}{l}\text { 1 Increase } \\
\text { in Post } \\
\text { Reaction }\end{array}$ & $\begin{array}{l}\text { 1 Increase } \\
\text { in Post } \\
\text { Share }\end{array}$ & $\begin{array}{l}\text { 1 Increase } \\
\text { in Click }\end{array}$ \\
\hline Aggregate & 1,203 & -15 & 6,177 & - & - & - \\
Brand Awareness & 1,346 & - & - & 1,262 & 4,789 & - \\
Post Engagement & 822 & $-2,936$ & - & -39 & 1,779 & - \\
Video Views & 681 & $-15,572$ & - & 0.001 & - & 0.002 \\
\hline
\end{tabular}

Comparing across the predictor variables, results begin to show the relational impact of each variable (see Table 5). It appears that the initial hypotheses are at least partially supported with the results such that as the cognitive elaboration associated with post-level engagement increases, so does the associated ad recall. For an increase in one comment, there was an associated increase in more than 6,000 people who recalled the ad. For advertisers who chose brand awareness as their objective an increase in one post share was associated with an increase in nearly 5,000 people to recall the ad whereas an increase in one reaction is associated with an increase in 1,262 people to recall the ad.

When it comes to ad recall, the advertisers who chose brand awareness appear to benefit the most. Comparing across ad spend, an increase in $\$ 1$ ad spend was associated with an increase in 1,346 in ad recall for brand awareness advertisers. Brand awareness were also the only group of advertisers who found no significant negative predictors of ad recall. Thus, the negative effects associated with ad frequency may be less for brand awareness advertisers.

Ad frequency was found to have a strong and negative significant relationship with ad recall both at the aggregate level and across all models except for the model whose group of advertisers chose brand awareness as their ad objective. Advertisers investing in Facebook advertising should be warry of the negative impact of ad fatigue due to repeat exposure. This sample of advertisers had an average ad frequency of 1.45, meaning on average each ad was delivered to one and a half people. By lowering impressions to one, it may be possible for an advertiser to avoid this negative effect. 


\section{Implications, Limitations \& Future Research}

Social media provides a viable channel to drive brand awareness, sales and ultimately, as provided by this study, ad recall. By narrowing into the results presented in Table 5, managers can compare across ad spend and engagement activities related to their brand communications. The research suggests that comments have a more important relationship with ad recall than those engagements with lower cognitive elaboration such as clicks, reactions and shares. This provides support for making brand awareness a priority for social media marketing. However, there may be strategic benefits for advertisers who focus first on brand awareness prior to retargeting. Facebook advertisers designing social media campaigns should also critically consider the negative impact of ad frequency. Ad recall represents the number of people predicted to recall an ad within two days of seeing it. Likely extenuated through overall social media fatigue (Bright, Kleiser \& Grau, 2015), repetition also appears to be a driving force behind the significant negative impact on recall from this sample of advertisers.

Of the limitations, the study relies upon behavioral data collected through Facebook owned platforms. While on one hand this provides a consolidated source for data, it also limits the measurement effects to the platform. Future studies may examine the effects of reactions, as they are experienced as positive (i.e., haha, like, love) or negative responses (i.e., sad, angry) and may extend the literature on emotion as it relates to attitude. Last, without further research, it's difficult to know whether this study accurately represents the general Facebook population.

\section{CONCLUSION}

The Facebook Ad Recall Lift metric that is available to Facebook advertisers is an example of an estimated metric (i.e., predicted algorithmically through data science) that uses machine learning and provides new opportunities to support past literature while driving future engagement research. Furthermore, with data collected from social media platforms, advertisers have the potential to examine and explain consumers' interactions and responses to brand communication in a natural consumer setting (Voorveld, 2019). The analysis procedure presented in this study can also be extended beyond the study of recall to answer calls for future research using behavioral data.

\section{ENDNOTE}

1. SAS (2014) SAS Institute Inc., Cary, North Carolina USA

\section{REFERENCES}

Aaker, D.A., \& Myers, J.G. (1987). Advertising management. Englewood Cliffs: Prentice-Hall International.

Abrams, Z., \& Vee, E. (2007, December). Personalized ad delivery when ads fatigue: An approximation algorithm. In International Workshop on Web and Internet Economics (pp. 535-540). Springer, Berlin, Heidelberg.

Alhabash, S., McAlister, A.R., Lou, C., \& Hagerstrom, A. (2015). From clicks to behaviors: The mediating effect of intentions to like, share, and comment on the relationship between message evaluations and offline behavioral intentions. Journal of Interactive Advertising, 15(2), 82-96.

Alhabash, S., Mundel, J., \& Hussain, S.A. (2017). Social Media Advertising: Unraveling the Mystery Box. In Digital Advertising (pp. 285-299). Routledge.

Appel, M., \& Richter, T. (2010). Transportation and need for affect in narrative persuasion: A mediated moderation model. Media Psychology, 13(2), 101-135.

Araujo, T., Copulsky, J.R., Hayes, J.L., Kim, S.J., \& Srivastava, J. (2020). From Purchasing Exposure to Fostering Engagement: Brand-Consumer Experiences in the Emerging Computational Advertising Landscape. Journal of Advertising, pp. 1-18. 
Batra, R., \& Ray, M.L. (1986). Affective responses mediating acceptance of advertising. Journal of Consumer Research, 13(2), 234-249.

Batra, R., \& Stephens, D. (1994). Attitude effects of ad-evoked moods and emotions: The moderating role of motivation. Psychology and Marketing, 11(3), 199-215.

Boller, G.W., \& Olson, J.C. (1991). Experiencing ad meanings: Crucial aspects of narrative/drama processing. ACR North American Advances.

Bossetta, M. (2018). The digital architectures of social media: Comparing political campaigning on Facebook, Twitter, Instagram, and Snapchat in the 2016 US election. Journalism \& Mass Communication Quarterly, 95(2), 471-496.

Brechman, J.M., \& Purvis, S.C. (2015). Narrative, transportation and advertising. International Journal of Advertising, 34(2), 366-381.

Brettel, M., Reich, J.C., Gavilanes, J.M., \& Flatten, T.C. (2015). What drives advertising success on Facebook? An advertising-effectiveness model: Measuring the effects on sales of "likes" and other social-network stimuli. Journal of Advertising Research, 55(2), 162-175.

Bright, L.F., Kleiser, S.B., \& Grau, S.L. (2015). Too much Facebook? An exploratory examination of social media fatigue. Computers in Human Behavior, 44, 148-155.

Brodie, R.J., Ilic, A., Juric, B., \& Hollebeek, L. (2013). Consumer engagement in a virtual brand community: An exploratory analysis. Journal of Business Research, 66(1), 105-114.

Bucher, T. (2017). The algorithmic imaginary: Exploring the ordinary effects of Facebook algorithms. Information, Communication \& Society, 20(1), 30-44.

Burke, M.C., \& Edell, J.A. (1986). Ad reactions over time: Capturing changes in the real world. Journal of Consumer Research, 13(1), 114-118.

Busselle, R., \& Bilandzic, H. (2009). Measuring narrative engagement. Media Psychology, 12(4), 321347.

Chang, C. (2009). "Being Hooked" By Editorial Content: The Implications for Processing Narrative Advertising. Journal of Advertising, 38(1), 21-34.

Ching, R.K., Tong, P., Chen, J.S., \& Chen, H.Y. (2013). Narrative online advertising: Identification and its effects on attitude toward a product. Internet Research.

Chung, H., \& Zhao, X. (2003). Humour effect on memory and attitude: Moderating role of product involvement. International Journal of Advertising, 22(1), 117-144.

Clement, J. (2019, August 14). Number of social media users worldwide 2010-2021. Retrieved from https://www.statista.com/statistics/278414/number-of-worldwide-social-network-users/

Danaher, P.J., \& Mullarkey, G.W. (2003). Factors affecting online advertising recall: A study of students. Journal of Advertising Research, 43(3), 252-267.

Davis, J.L., \& Chouinard, J.B. (2016). Theorizing affordances: From request to refuse. Bulletin of Science, Technology \& Society, 36(4), 241-248.

Facebook. (n.d.). About Facebook metrics being removed. Retrieved December 15, 2020, from https://www.facebook.com/business/help/1695754927158071?id=354406972049255

Facebook. (n.d.). About the Estimated Ad Recall Lift (People) Metric. Retrieved December 10, 2019, from https://www.facebook.com/business/help/1029827880390718?id=429023050853196

Fay, B., Keller, E., \& Larkin, R. (2019). How measuring consumer conversations can reveal advertising performance. Journal of Advertising Research, 59(4), 433-439.

Feng, Y., Xie, Q., \& Lou, C. (2019). The Key to 360-Degree Video Advertising: An Examination of the Degree of Narrative Structure. Journal of Advertising, 48(2), 137-152.

Green, M.C., \& Brock, T.C. (2002). In the mind's eye: Transportation-imagery model of narrative persuasion.

Hennig-Thurau, T., Gwinner, K.P., Walsh, G., \& Gremler, D.D. (2004). Electronic word-of-mouth via consumer-opinion platforms: What motivates consumers to articulate themselves on the Internet? Journal of Interactive Marketing, 18(1), 38-52.

Kempf, D.S. (1999). Attitude formation from product trial: Distinct roles of cognition and affect for hedonic and functional products. Psychology and Marketing, 16(1), 35-50. 
Kent, R.J. (2002). The Effects of Media-Source Cues in Ad Recall Tests. Journal of Current Issues \& Research in Advertising, 24(1), 1-9.

Kim, C., \& Yang, S.U. (2017). Like, comment, and share on Facebook: How each behavior differs from the other. Public Relations Review, 43(2), 441-449.

Kim, J., \& Morris, J.D. (2007). The power of affective response and cognitive structure in product-trial attitude formation. Journal of Advertising, 36(1), 95-106.

Kim, J., Baek, Y., \& Choi, Y.H. (2012). The structural effects of metaphor-elicited cognitive and affective elaboration levels on attitude toward the ad. Journal of Advertising, 41(2), 79-98.

Kim, T., Kim, H., \& Kim, Y. (2019). How Do Brands' Facebook Posts Induce Consumers' e-Word-ofMouth Behavior?: Informational versus Emotional Message Strategy: A Computational Analysis. Journal of Advertising Research, 59(4), 402-413.

King, K.W., \& Tinkham, S.F. (1989). The learning and retention of outdoor advertising. Journal of Advertising Research.

Klimmt, C., \& Vorderer, P. (2003). Media psychology "is not yet there": Introducing theories on media entertainment to the presence debate. Presence: Teleoperators \& Virtual Environments, 12(4), 346-359.

Lambert, B. (2018). Report: How modern marketers measure advertising effectiveness. Retrieved from https://blog.adstage.io/2017/07/ 11/measure-advertising-effectiveness

Lee, D., Hosanagar, K., \& Nair, H.S. (2018). Advertising content and consumer engagement on social media: Evidence from Facebook. Management Science, 64(11), 5105-5131.

Lipsman, A., Mudd, G., Rich, M., \& Bruich, S. (2012). The power of "like": How brands reach (and influence) fans through social-media marketing. Journal of Advertising Research, 52(1), 40-52.

MacInnis, D.J., \& Price, L.L. (1987, March). The Role of Imagery in Information Processing: Review and Extensions. Journal of Consumer Research, 13, 473-491.

McQuarrie, E.F., \& Mick, D.G. (1999). Visual rhetoric in advertising: Text-interpretive, experimental, and reader-response analyses. Journal of Consumer Research, 26(1), 37-54.

Monroe, B.L., Pan, J., Roberts, M.E., Sen, M., \& Sinclair, B. (2015). No! Formal theory, causal inference, and big data are not contradictory trends in political science. PS, Political Science \& Politics, 48(1), 71.

Moriwaki, D., Fujita, K., Yasui, S., \& Hoshino, T. (2019). Fatigue-Aware Ad Creative Selection. arXiv, arXiv-1908.

Nan, X., \& Faber, R.J. (2004). Advertising theory: Reconceptualizing the building blocks. Marketing Theory, 4(1-2), 7-30.

O'Brien, H.L., \& Toms, E.G. (2010). The development and evaluation of a survey to measure user engagement. Journal of the American Society for Information Science and Technology, 61(1), $50-69$.

Oh, J., \& Sundar, S.S. (2015). How Does Interactivity Persuade? An Experimental Test of Interactivity on Cognitive Absorption, Elaboration, and Attitudes. Journal of Communication, 65(2), 213-236. https://doi.org/10.1111/jcom.12147

Oh, J., Bellur, S., \& Sundar, S.S. (2018). Clicking, assessing, immersing, and sharing: An empirical model of user engagement with interactive media. Communication Research, 45(5), 737-763.

Pavelchak, A. (1988). The Super Bowl: An Investigation into the Relationship Among Program Context, Emotional Experience, and Ad Recall. The Journal of Consumer Research, 15(3), 360-367. Web.

Petty, R.E., \& Cacioppo, J.T. (1986). Communication and Persuasion: Central and Peripheral Routes to Attitude Change. Springer-Verlag: New York, NY.

Petty, R.E., \& Wegener, D.T. (1999). The elaboration likelihood model: Current status and controversies. In S. Chaiken \& Y. Trope (Eds.), Dual-Process Theories in Social Psychology (pp. 41-72). The Guilford Press: New York, NY.

Pham, M.T., Cohen, J.B., Pracejus, J.W., \& Hughes, G.D. (2001, September). Affect Monitoring and the Primacy of Feelings in Judgment. Journal of Consumer Research, 28. 
Precourt, G. (2014). What Do We Know About Social Media? Journal of Advertising Research, 54(1), 45. doi:10.2501/jar-54-1-004-005

Precourt, G. (2016). How Does Recall Work in Advertising? Journal of Advertising Research, 56(3), 229. doi: 10.2501/jar-2016-031

Rappaport, S.D. (2014). Lessons learned from 197 metrics, 150 studies, and 12 essays: A field guide to digital metrics. Journal of Advertising Research, 54(1), 110-118.

SAS 9.4 Software. (n.d.). Retrieved April 8, 2020, from https://www.sas.com/en_us/software/sas9.html

Sciarrino, J., Wilcox, G.B., \& Chung, A. (2020). Measuring the effectiveness of Peer-to-Peer Influencer Marketing in an Integrated Brand Campaign. Journal of Digital and Social Media Marketing.

Shmueli, G., \& Koppius, O.R. (2011). Predictive analytics in information systems research. MIS Quarterly, pp. 553-572.

Slater, M.D., \& Rouner, D. (2002). Entertainment — education and elaboration likelihood: Understanding the processing of narrative persuasion. Communication Theory, 12(2), 173-191.

Smit, E.G., Van Meurs, L., \& Neijens, P.C. (2006). Effects of advertising likeability: A 10-year perspective. Journal of Advertising Research, 46(1), 73-83.

Stroud, N.J., \& Muddiman, A. (2019). Social Media Engagement With Strategy-and Issue-Framed Political News. Journal of Communication, 69(5), 443-466.

Venkatadri, G., Andreou, A., Liu, Y., Mislove, A., Gummadi, K.P., Loiseau, P., \& Goga, O. (2018, May). Privacy risks with Facebook's pii-based targeting: Auditing a data Broker's advertising interface. In 2018 IEEE Symposium on Security and Privacy (SP) (pp. 89-107). IEEE.

Voorveld, H.A. (2019). Brand Communication in Social Media: A Research Agenda. Journal of Advertising, 48(1), 14-26.

Wilcox, G., \& Sussman, K. (2014). Lead-generating social media strategies using the social media performance model: The B2B connection. Journal of Digital \& Social Media Marketing, 2(1), $70-78$.

Wilcox, G.B., \& Kim, K.O.K. (2012). Social media measurement: A time series analysis approach. Marketing Management Journal, 22(2), 99-101.

Wilcox, G.B., \& Moore, M. (2016). The impact of social media on return on investment: Registrations and revenue. Journal of Digital \& Social Media Marketing, 3(4), 363-371.

Wouters, J., \& Wetzels, M. (2006). Recall effect of short message service as a complementary marketing communications instrument. Journal of Advertising Research, 46(2), 209-216.

\section{APPENDIX}

\section{FIGURE 1 \\ FACEBOOK'S MEASUREMENT OF AIDED RECALL USED TO PREDICT FACEBOOK AD RECALL LIFT}

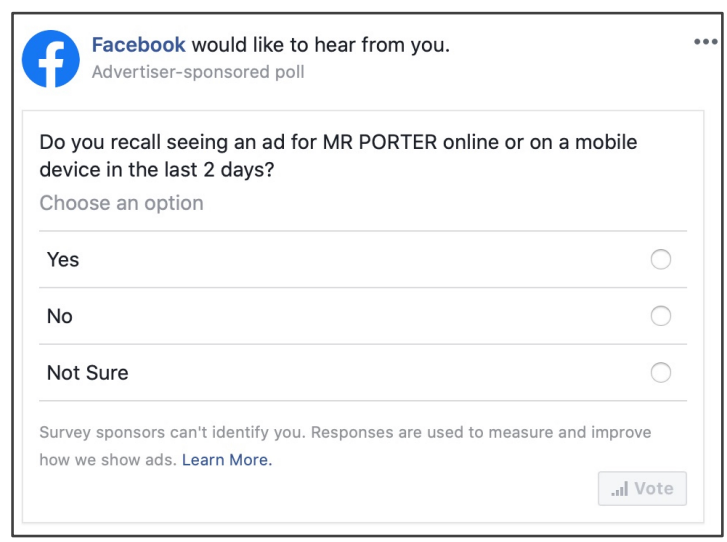

14 Journal of Marketing Development and Competitiveness Vol. 15(4) 2021 